\title{
Stripping and Excavating Control Technology of Spontaneous Combustion Area in Shallow Buried Coal Seam
}

\author{
Zhang Xin-hai ${ }^{1,2 *}$, Wang Kai ${ }^{1,2}$, Dou Kai ${ }^{1,2}$, Li Jing-wen ${ }^{1,2}$, \\ ${ }^{1}$ Key Laboratory of Western Mine and Hazard Prevention, Ministry of Education of China, Xi'an, 710054, China \\ ${ }^{2}$ School of Safety Science and Engineering, Xi'an University of Science and Technology, Xi'an, 710054, China
}

\begin{abstract}
The article expounds the principle, steps and results of detecting the fire source by the magnetic method. Based on the determination of the fire source range, by analyzing the actual situation of the shallow coal seam, comparing the advantages and disadvantages of the three different treatment methods and the applicable situation, a stripping is proposed. The law governs the fire zone and applies it in the governance zone. The results show that the magnetic detection technology has high detection accuracy and fast efficiency, and the stripping method has good fire extinguishing effect in the fire area, high safety, large amount of residual coal recovery, and is suitable for shallow buried fire sources. The study provides a scientific basis for fire detection, treatment, coal resource recovery, environmental protection and economic development in open-pit mine fire areas.
\end{abstract}

\section{Introduction}

Coal field fires occur all over the world. China suffers from the most serious coal fire disaster in the world. After the underground coal seam catches fire, it usually spreads along the coal seam, with a large burning area and long duration [1-3]. According to incomplete statistics, the annual amount of coal burned by coal fires reaches 20 million tons, which is equivalent to Turkey's total coal output of 20.8 million tons in 2017. Coal fire disasters not only cause the waste of resources, but also cause environmental pollution, property loss and other hazards, which affect the local economic development and ecological environment, and the treatment of coal field fires is imminent [4-5]. After the underground coal seam catches fire, it usually spreads along the coal seam. Its burning area is large and lasts for a long time.

Existing fire source detection technologies include remote sensing method [6], gas detection method [7], temperature detection method [8], infrared thermal imaging method [9-10], radon method and magnetic method [11-13]. Magnetic exploration has the characteristics of high efficiency, low cost, and is not restricted by geographical conditions [14-15]. It has a very broad application prospect in coal fire detection, which has caused a lot of research by scholars at home and abroad. In the United States, Taku et al. successfully determined the location and range of the fire area through the analysis and processing technology of magnetic anomaly data, and the results obtained and the results obtained by the temperature measurement method are mutually confirmed [16]. Wang Wenzheng simulated a five-layer gradient burn geological model and analyzed the influence of roof lithology on geomagnetic anomalies.
There are obvious differences in magnetic anomalies in different lithological burns, and the magnetic anomalies become stronger as the temperature increases [17]. Shao et al. [18] determined through experiments that newly formed magnetite and thermal residual magnetization are the root causes of magnetic anomalies in the fire zone. The position of the fire zone was determined by the magnetic method and verified with the position determined by the electric potential method.

Sidaoliu Coal Mine is located near the Gonggou tunnel on Zhundong Railway, Inner Mongolia. The main mineable coal seam is the No. 5 coal seam. This coal seam belongs to the middle-lower Jurassic Yan'an coal-measure strata. It is a medium-thick coal seam. The coal seam is stable and structural Simple, the coal seam is inclined to the southwest with an inclination angle of 1 to $3^{\circ}$. Because the No. 5 coal seam adopts room and pillar mining technology and is shallowly buried, the roadways intersect each other, and the air leakage from the surface gap is serious. A large-scale high temperature phenomenon occurred, large-scale cracks occurred in the concrete stone slope protection wall, local stone slope protection collapsed seriously, and dense smoke emerged from the cracks, which seriously threatened the safety of railway transportation.

\section{2 fire detection}

\subsection{Magnetic analysis}

There is a geomagnetic field around the earth with a wide range of distribution, from the core to the edge of the magnetosphere in space. Another part of the internal stable 
magnetic field is the magnetic field generated by the rock minerals and geological bodies in the crust under the action of the basic magnetic field magnetization, which is called the crust magnetic field or magnetic anomaly. Magnetic anomalies are the result of the effects of paramagnetic, diamagnetic and ferromagnetic materials. The susceptibility of diamagnetic materials is less than zero, and the susceptibility of paramagnetic materials is greater than zero. The continuous change and development of the combustion state of coal fires, and the appearance of different coal fire combustion stages (occurrence, development, extinguishment), make the heat difference in the fire area, and the magnetic size of coal and rock will also be different. Studies have shown that the Ordos coal-forming basin, like many coal fields, has a large amount of mineral components that can form ferromagnetic materials at high temperatures. Therefore, the high temperature fire zone will produce obvious magnetic anomalies. The characteristics of magnetic anomalies in the coal rocks of the Ordos coal-forming basin at different temperatures are as follows:

Table 1.The magnetic characteristics of coal at different combustion stages in the coal fire area

\begin{tabular}{|c|c|c|c|}
\hline Burning phase & $\begin{array}{l}\text { Combustion } \\
\text { characteristics }\end{array}$ & $\begin{array}{l}\text { Temperature } \\
\text { of } \\
\text { underground } \\
\text { combustion } \\
\text { body }\left({ }^{\circ} \mathrm{C}\right) \\
\end{array}$ & $\begin{array}{c}\text { Magnetic } \\
\text { characteristics }\end{array}$ \\
\hline $\begin{array}{c}\text { Initial } \\
\text { spontaneous } \\
\text { combustion }\end{array}$ & $\begin{array}{l}\text { Weathering } \\
\text { period }\end{array}$ & normal & $\begin{array}{c}\text { No or weak } \\
\text { magnetic }\end{array}$ \\
\hline $\begin{array}{l}\text { Initial } \\
\text { spontaneous } \\
\text { combustion }\end{array}$ & Oxidation period & $100 \sim 250$ & $\begin{array}{c}\text { No or weak } \\
\text { magnetic }\end{array}$ \\
\hline $\begin{array}{c}\text { Initial } \\
\text { spontaneous } \\
\text { combustion }\end{array}$ & $\begin{array}{c}\text { Spontaneous } \\
\text { combustion } \\
\text { period }\end{array}$ & $250-400$ & $\begin{array}{c}\text { No or weak } \\
\text { magnetic }\end{array}$ \\
\hline $\begin{array}{l}\text { Formation } \\
\text { center }\end{array}$ & $\begin{array}{l}\text { Combustion } \\
\text { center formation } \\
\text { period }\end{array}$ & $400 \sim 600$ & $\begin{array}{c}\text { Enhancement, } \\
\text { big change }\end{array}$ \\
\hline $\begin{array}{l}\text { Formation } \\
\text { center }\end{array}$ & $\begin{array}{c}\text { Combustion } \\
\text { system formation } \\
\text { period }\end{array}$ & $600 \sim 900$ & Drop \\
\hline $\begin{array}{l}\text { Combustion } \\
\text { development }\end{array}$ & Burning period & $>900$ & Non-magnetic \\
\hline $\begin{array}{l}\text { Turn off and } \\
\text { cool down }\end{array}$ & $\begin{array}{l}\text { Sulfur, Glauber's } \\
\text { salt and other } \\
\text { minerals } \\
\text { precipitation } \\
\text { period }\end{array}$ & $400 \sim 100$ & Enhance \\
\hline $\begin{array}{l}\text { Turn off and } \\
\text { cool down }\end{array}$ & Dormant period & $200 \sim 100$ & Enhance \\
\hline $\begin{array}{l}\text { Turn off and } \\
\text { cool down }\end{array}$ & Extinction period & $\begin{array}{c}100 \sim \\
\text { homoeothermy }\end{array}$ & Enhance \\
\hline
\end{tabular}

Based on this, it is possible to analyze whether there is a high temperature anomaly zone in the formation by conducting magnetic anomaly detection on the surface.

\subsection{Fire location detection and analysis}

Delineate the approximate detection range according to the drawings provided by the mine and the actual conditions of the mining area, use GPS to control the coordinates of the four corner points, and then divide the measurement area with a tape measure to calculate the coordinate position of each grid node. The point position accuracy is within $1 \mathrm{~m}$, and there is a measuring point every $10 \sim 15$ (the measuring point interval is generally $15 \mathrm{~m}$, and the magnetic force change is abnormally obvious area, and then the measuring points are encrypted.

The measuring points are arranged in a mesh pattern. In the actual detection process, 379 measuring points were designed and arranged due to the actual surface conditions and finally 356 measuring points were measured. The data was differentiated and analyzed to obtain the magnetic measurement value plan. Knowable:

The red protruding area shown in the northwestern magnetic anomaly contour map (Figure 1) and the southeast magnetic anomaly contour map (Figure 2) shows the red protruding area as the magnetic anomaly high temperature area.

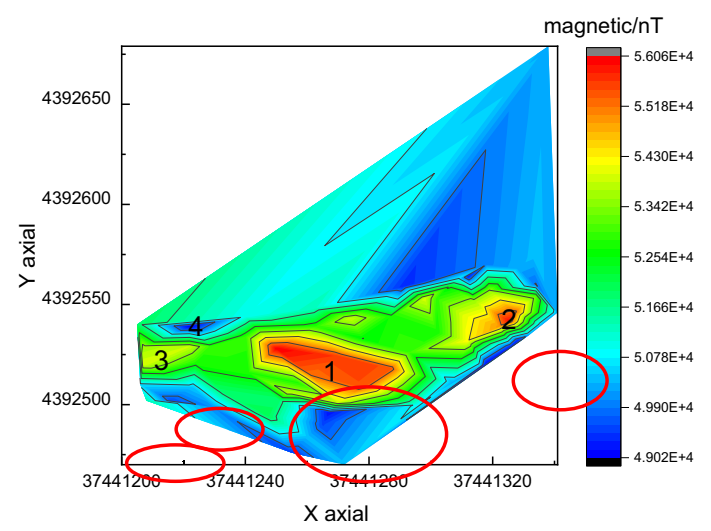

Figure 1. Stereograph of magnetic outliers in Northwestern China

(1) Areas 2 and 3 centered on (4392524, 37441212) and $(4392543,37441325)$ have abnormal areas of magnetic increase, but the magnetic increase is not obvious. Its abnormal radius is about $10 \mathrm{~m}$. This area should be caused by underground magnetic materials. The possibility of temperature rise cannot be ruled out.

(2) The magnetic anomaly core is demarcated by the coordinates of the northeast area $(4392517,37441287)$, the northwest area $(4392503,37441273)$, the southeast area $(4392533,37441247)$, and the left point (4392521, 37441247 ) in the southwest area. In the area (area 1 of the abnormal area in the figure), the magnetism changes drastically, with positive and negative anomalies intersecting, and the range of changes is large. The critical area of positive and negative magnetic anomalies is often the result of temperature rise and should be taken seriously

(3) The absolute magnetic value of the area centered at the coordinate point of area $1(4392518,37441268)$ tends to increase significantly. There may be a high temperature in the coal seam, or it may be affected by magnetic materials such as burnt rock. 


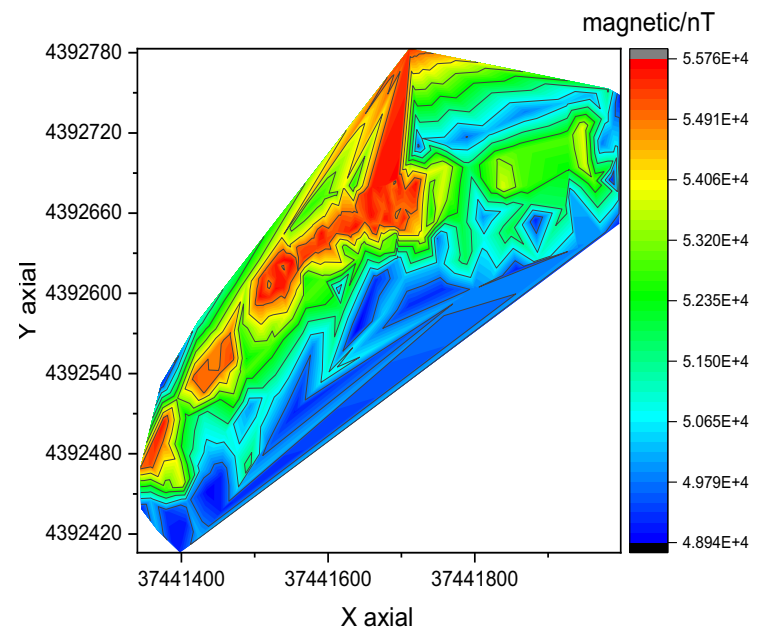

Figure 2. Three-dimensional map of magnetic anomalies in Southeastern China

The following abnormalities occurred in this area:

(1) Take the coordinate points $(4392468,37441359)$, $(4392501,37441381)$ and (4392476,37441348) and $(4392502,37441372)$ as the boundary of area 1 , and use the coordinate points (4392525,37441429), $(4392550,37441468)$ and (4392568,37441463) and $(4392536,37441416)$ are the boundaries of area 2 . These two areas are the abnormal non-core areas of the detection result of this method, and there are abnormal areas of magnetic increase, but the increase of magnetism is not obvious. The high temperature area is rectangular, and the preliminary judgment of this area should be caused by the interference of magnetic materials, but the possibility of changes in coal magnetic properties caused by the high temperature of underground coal seams cannot be ruled out.

(2) Use the coordinate points $(4392649,37441715)$, (439220,37441568), and (4392636,37441555), $(4392675,37441645)$ and $(4392779,37441702)$ as the boundary to divide the core area of the magnetic anomaly (abnormal area 3 in the figure) Area), the magnetic changes are drastic, positive and negative anomalies intersect, and the range of change is large. The critical area of positive and negative magnetic anomalies is often the result of temperature rise and should be paid close attention to.

(3) The magnetic anomaly value of the region centered on the coordinate points of 3 regions $(4392665,37441665)$ tends to increase significantly, and the region is quite large. It is judged that this region is an underground coal seam high temperature area, and there is also a magnetic material influence area such as burnt rock.

\section{Fire zone governance}

\subsection{Determination of control technology}

Commonly used fire-fighting techniques in coal fields include loess covering method, perforation grouting method, stripping method, etc. [13] The loess covering method is simple to operate and the construction speed is fast, but it is difficult to achieve the expected effect when the terrain is complex, and it is difficult to completely control the fire in a short time. It is suitable for shallow fire areas in coal seams with flat ground, sufficient materials and light fire. The perforation grouting method is simple in construction and quick in effect, but when the subsidence area, cracks and goaf are criss-crossed, the amount of grouting is large, the grout is easily lost, and the pertinence is weak. It is suitable for deep and heavy fire in the goaf. The stripping method has a thorough fire extinguishing effect and can recover a large amount of coal resources. The construction preparation is simple and there are many idle machinery in the society, but it is only suitable for coal fields with shallow coal seams. Comparing the advantages and disadvantages of the above methods and combining factors such as the depth of the coal seam and the small inclination angle, it is proposed to use the stripping method to completely control the fire area. By stripping the overlying layer of the coal seam in the high temperature affected area near the railway, digging out the fire area to affect the coal seam, and then filling the stripping area, restoring the surface vegetation, to achieve the purpose of thoroughly controlling the fire area.

\subsection{Feasibility of stripping}

This area is a plateau erosive landform, with bedrock exposed along both sides of the valley. The lithology is characterized by sandstone, glutenite, mudstone, siltstone, and conglomerate. The rock quality is mostly medium, weak to semi-hard rock. The roof and floor rocks of the coal seam have low strength and are weak rocks with poor stability. There are coal seam outcrops in the Gonggou section of the Zhundong Railway. The buried depth of No. 5 coal seam is only about $4 \mathrm{~m}$ at the railway line, about $50 \mathrm{~m}$ at the deepest part of the top of the mountain, the coal thickness is $2.8 \mathrm{~m}$, and the maximum width of the hillside is $<100 \mathrm{~m}$. The shallow coal seam depth is suitable for stripping fire control. The proven high-temperature area is located on the northwest side of the railway, about $60 \mathrm{~m}$ away from the railway tunnel, which meets the needs of excavating coal seams between the railway tunnel and the fire area, isolating the fire area and protecting the railway tunnel. There are open mining pits and ravines in the surrounding area to facilitate the stripping and dumping. The stripping works and fire fighting water can be taken from nearby mines by tankers. Therefore, the stripping method can not only control the coal seam outcrop fire area, completely eliminate the harm of coal seam fire, but also recover a large amount of high-quality coal resources remaining in the old goaf.

\subsection{Stripping parameters}

The calculated surface excavation boundary is: the length of the excavation boundary of the northwest side of the railway is $380 \mathrm{~m}$, the length of the southwest is $140 \mathrm{~m}$, the length of the excavation of the northeast is $210 \mathrm{~m}$, and the coal seam cover rock is about $40 \mathrm{~m}$. The area of the coal seam is about $25899.87 \mathrm{~m} 2$.

The calculation formula for recoverable residual coal 
is:

$$
Q=K d S h n
$$

Where: $\mathrm{Q}$ is the recoverable residual coal quantity, $\mathrm{t}$; $\mathrm{K}$ is the resource recovery rate, taken as $97 \%$; $\mathrm{d}$ is the coal bulk density, which is $1.3 \mathrm{t} / \mathrm{m}^{3}$; $\mathrm{S}$ is the area of the coal seam to be mined, $\mathrm{m}^{2}, \mathrm{H}$ is the thickness of the coal seam, $3 \mathrm{~m}$; $\mathrm{n}$ In order to recover the residual coal rate of the original house, the original recovery rate is about $40 \%$, but considering the influence of the fire area, the residual coal amount is calculated as $50 \%$.

Calculated by formula:

$\mathrm{Q}=25899.87 \mathrm{~m}^{2} \times 3 \mathrm{~m} \times 1.3 \mathrm{t} / \mathrm{m}^{3} \times 0.97 \times 0.5=16329.9 \mathrm{t}$

It is calculated by formula that the area of the coal seam excavated on the northwest side of the railway is $25899.87 \mathrm{~m}^{2}$.

The calculation formula of stripping amount is:

$$
W_{\text {Stripping amount }}=\mathrm{SL}
$$

In the formula: $\mathrm{W}$ is the amount of stripping and excavation, $\mathrm{m}^{3} ; \mathrm{S}$ is the area of the mined coal seam, $\mathrm{m}^{2}$,

Calculate $W_{\text {Stripping amount }}=\mathrm{SL}=25899.87 \times 40=$ $1035994.8 \mathrm{~m}^{3}$

Stripping ratio: stripping volume/recoverable residual coal volume $=1035994.8 \mathrm{~m}^{3} / 16329.9=63.4 \mathrm{~m}^{3} / \mathrm{t}$.

Slope stability: According to the shape of the coal seam, the inclination of the coal seam in the treatment area is gentle, and there are no faults and magmatic rock intrusions at an approximate level. The landslide mode is determined to be a circular arc landslide. The strata in the stripping area are Quaternary sand, siltstone, and coal seams from top to bottom. The calculation of the model shows that when the height of the bank reaches $40 \mathrm{~m}$ and the slope angle is $35^{\circ}$, the slope stability coefficient is 1.26 , which can basically remain stable. The side of the railway tunnel is the original stripped excavation slope, and its first and second step slopes are both $33 \sim 35^{\circ}$, which remain stable for a long time, so the stripped slope angle is determined to be $33 \sim 35$.

\subsection{Construction process}

The process is: topsoil stripping__advanced water injection (or grouting)—rock crushed by breakerhydraulic excavator picking__ dump truck transported to dump site for disposal_loader leveling dump site- removal Burning body_loess covered coal seam outcrop_-backfill excavation pit_-greening.

\subsection{Construction Equipment}

The stripping adopts the single bucket-truck process, using $142.5 \mathrm{~m}^{3}$ hydraulic backhoes, $7432 \mathrm{t}$ dump trucks, $3 \mathrm{KQ} 150$ drilling rigs, and $4 \mathrm{~m}^{3}$ loaders.

\subsection{Stripping plan}

The digging steps are layered horizontally, and the height of the steps is $10 \mathrm{~m}$. Stripping and digging the bench adopts the end face mining method, and the mining bandwidth is $12 \mathrm{~m}$. The rock is pierced and exploded, and the frozen soil needs to be pierced and exploded in the freezing season. It is picked and loaded by a $2.5 \mathrm{~m} 3$ hydraulic excavator, transported by a $32 \mathrm{t}$ dump truck, and the loader completes auxiliary operations such as leveling, cleaning the working face and transportation channels.

The excavation boundary of the northwest treatment area is a hillside parallel to the railway line, which is about $30 \mathrm{~m}$ higher than the original reclamation platform. $10 \mathrm{~m}$ above the platform is a step divided into three excavation platforms. The excavation work line is located on the southeast side of the mountain and parallel railway lines are arranged. The stripping and digging face of the fourth, fifth and sixth platforms are located about $10 \mathrm{~m}, 20 \mathrm{~m}$, and $30 \mathrm{~m}$ below the original reclamation platform. The residual coal will be recovered during the sixth stripping.

Strip the coal seam around the fire area, and the distance between the stripping position and the hightemperature coal body should not be less than $10 \mathrm{~m}$. Do not move the high-temperature fire area, and eventually form an isolated island at the position of the hot coal seam. In order to prevent the deterioration of the fire caused by the fire separation, the outcrop first The boundary of the deep fire zone is grouted to prevent the fire from spreading further. Then strip the loose outcropping coal fire, and form a covering layer through grouting and loess covering to reduce air leakage and oxygen supply at the hightemperature fire source to extinguish the fire. Use large flow of water to pour the fire area to extinguish the fire, start pour water from the surrounding area, and gradually advance to the high temperature core. When grouting or water injection, the coal seam surface should be covered with loess, and water and coal vapor explosion should be prevented during the fire fighting process. After the temperature in the coal seam fire area drops sufficiently, the original high-temperature coal is stripped. During the stripping process, water, grouting and other cooling fire extinguishing materials should be prepared. Once a residual fire is found or re-ignition occurs, the fire should be extinguished in time. Backfill in time after coal seam recovery.

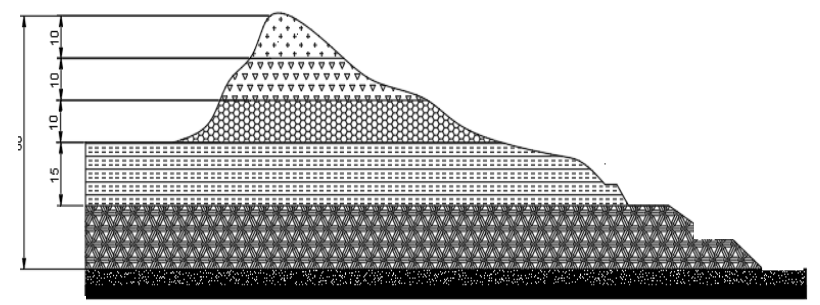

Figure 3. Topography of stripping area in northwest

\section{Evaluation of fire extinguishing effect}

Excavation and stripping are used to extinguish the fire in this fire area. Only the outcrops of coal seam caused by stripping and excavation appear at the bottom of the pit. It is not necessary to set up all monitoring holes in the stripping pit. The monitoring holes are arranged on the surface boundary of the stripping and excavation, and are arranged linearly with a distance of $100 \mathrm{~m}$. A total of four detection holes are arranged. The design selects $\varphi 108$ ordinary welded steel pipe as the monitoring pipe, above 
is the screen part, the length of the screen is not less than $0.5 \mathrm{~m}$, the screen is composed of $\varphi 5 \mathrm{~mm}$ small holes, and the center spacing of the small holes is $10 \mathrm{~mm}$. The monitoring steel pipe is finally $0.5 \mathrm{~m}$ higher than the ground surface, and the pipe mouth is equipped with a detachable pipe cap, and the pipe mouth is sealed when the temperature is not measured. The depth of the monitoring hole is the floor of the burning coal seam.

The treatment area was treated according to the stripping method. After two years of comprehensive treatment, the stripping volume was $103,5994.8 \mathrm{~m}^{3}$. The fire extinguishing effect was significant. The surface fire characteristics disappeared. The cracks and smoke emission at the railway line hillside position were effectively treated. There is no abnormal area in the magnetic detection of the area. The gas temperature in each observation hole shows a continuous downward trend. The maximum temperature of the whole hole is less than $100^{\circ} \mathrm{C}$, and the maximum temperature of more than $90 \%$ of the observation holes is stable below $70^{\circ} \mathrm{C}$. The concentration of carbon monoxide in the observation holes continues to decrease, and the maximum value in the hole is less than $500 \mathrm{ppm}$. And the maximum concentration of carbon monoxide in more than $90 \%$ of the observation holes is stable below 100ppm.

\section{4 conclusion}

1) The magnetic method has high detection accuracy, low cost, easy operation, and has a wide range of application prospects in the detection of coal field fire areas.

2) The stripping method has a thorough fire extinguishing effect in the treatment of open-pit coal field fires. The construction is simple, and a large amount of coal resources can be recovered. It is suitable for coal field fire sources with shallow coal seams. After the extinguishment is over, the stripping pit is backfilled by internal drainage and covered with soil for greening.

3) Controlling fire areas is of great significance to protecting the atmospheric environment and maintaining a good ecological environment. Therefore, the coal seam fire must be quickly and thoroughly treated to eliminate hidden dangers and prevent accidents.

\section{references}

1.ZENG Qiang. Study on the thermal dynamic characteristics of combustion system for coal fires in xinjiang region[D]. Xuzhou: China University of Mining and Technology, 2012.

2.BP (2018) (2018) BP Statistical Review of World Energy

3.HOU Shen-jian, WANG DONG, ZHANG BO, et al. Development of China's coal rsources exploration in the new era[J]. Journal of Xi' an University of Science and Technology, 2019, 39 (2): 341 -346.

4.ZHANG Jianmin, GUAN Haiyan, CAO Daiyong, etc. Research and treatment of underground coal fire in
China [M]. Beijing: Coal Industry Press, 2008.

5.WU Jian-ming,ZHANG Jin-hua,WU Yu-guo. Detection on Spontaneous Combustion Area in Surface Mine and Study on Comprehensive Control Technology of Spontaneous Combustion Area[J]. Coal Engineering, 2012(02):53-56.

6.Slavecki R.J. Detection and location of subsurface coal fires; proceedings of the Proceedings of the third Symposium on Remote Sensing of Environment, F, 1964 [C].

7.Li J., Voight S., Kunzer C., et al. The Progress in Detecting of Coal Fire on Remote Sensing*The first Result of the Joint Sino-German Research Project on Innovative Technologies for Exploration, Extinction and Monitoring of Coal Fires in North China; proceedings of the 2005 Dragon Symposium, F, 2006 [C].

8.Elick Jennifer-M.. Mapping the coal fire at Centralia, Pa using thermal infrared imagery[J]. International Journal of Coal Geology, 2011, 87(3): 197-203.

9.Mine Fire Disaster Control Based on Infrared Imaging Technology[J].Coal Science and Technology, 2010, 38(1): 28-30.

10.ZHENG Xuezhao; JIA Yongxiao; GUO Jun; et al, Research status and prospect of coalfield fire monitoring technologies[J]. Industry and Automation, 2019,45(05):6-10+61.

11.ZHANG Xin-hai, NIU Heng, FEI Jin-biao. Using Measuring Radon Method to Detect Spontaneous Fire Location in Bayili Coal Mine[J]. Safety in Coal Mines, 2009, 40(7):29-30.

12.FEI Jin-biao, WEN HU, JIN Yong-fei. Application of radon method in detection of fire area in shallow coal seam[J]. Journal of Xi'an University of Science and Technology, 2018, 38(01): 26-30.

13.Song Yanchao, Wang Junlin, Shang Bing, Cui Hongxing, Wu Yunyun. Study on a new charcoal closed chamber method for measuring radon exhalation rate of building materials $[\mathrm{J}]$. Radiation Measurements, 2020.

14.Determining the Spontaneous Combustion Boundary of Northern Shaanxi Coal Seam Using High Precision Magnetic Method[J]. Advances in Geosciences, 2019, 9(5): 360-367.

15.ZHANG Xinhai; MIAO Yuhui; ZHANG Duo; et al, Experimental Study on Change Laws of Characteristic Gases and Magnetic in the Process of Coal Spontaneous Combustion[J]. Safety in Coal Mines, 2017,48(03):36-39.

16.Ide Taku-S, Crook N, Orr jr. et al, Magnetomete rmeasurements to characterize a subsurface coal fire[J]. International Journal of Coal Geology, 2011, 87(3): 190-196.

17.WANG Wen-zheng, MA Li-yang, LU Shi-yuan, et al. Forward Modeling for Magnetic Anomaly of Multilayer Burnt Rocks in Coal Fire Area[J]. Science Technology and Engineering, 2013, 13(20): 59245926. 
18.Shao Z, Wang D, Wang Y, et al. Theory and application of magnetic and self-potential methods in the detection of the Heshituoluogai coal fire, China[J]. Journal of Applied Geophysics, 2014, 104:64-74. 